возникаютврезультатепроизводственнойдеятельностичеловека - выемки, насыпи, отвалы, необходимо уточнять тахеометрической съемкой.

$$
* * *
$$

1. Инструкция по топографической съемке в масштабах 1:5000, 1:2000, 1:1000, 1:500 : [ГКИНП-02033-82: введен 01.01.1983]. - М. : Недра, 1985. - 151 с.

2. Инструкция по фотограмметрическим работам при создании цифровых карт и планов : [ГКИНП (ГНТА)-02-036-02: введен 01.08.2002]. - М. :ЦНИИГАиК, 2002. - 100 с.

3. Инструкция по развитию съемочного обоснования и съемке ситуации и рельефа с применением глобальных навигационных спутниковых систем ГЛОНАСС и GPS : [ГКИНП (ОНТА)-02-262-02: введен 01.03.2002]. - М. :Роскартография, 2002. - 56 с.

4. Руководство пользователя ГИС ArcGis.

Кочнева А.А., Голунцов А.С.

Методы создания координатной основы при проектировании автомобильных дорог

Санкт - Петербургский горный университет (Россия,Санкт - Петербург)

doi:10.18411/spc-12-04-2018-23

idsp: 000001:spc-12-04-2018-23

Проектирование протяженных объектов, таких как линейные сооружения, всегда было трудоемким процессом. Для этого необходима точная координатная основа.

Эффективное применение ВЛС связано с решением ряда задач. Основной вопрос состоит в построении цифровой модели рельефа, которая будет содержать минимальное количество точек лазерных отражений и полностью отражать рельеф местности.

Существуют различные классификации рельефа местности. В основном рельеф делят по крутизне земной поверхности. Согласно Инструкции [1] по характеру рельефа местность делится на следующие группы: - равнинная с углами наклона до 20, всхолмленная с углами наклона до 40, - пересеченная с углами наклона до 60, - горная и предгорная с углами наклона более 60. В качестве исходных данных предлагается использовать данные воздушного лазерного сканирования, а это огромный массив данных. В процессе классификации выделяется класс «земля», который используется для создания цифровых моделей рельефа. В предлагаемой методике необходимо еще уменьшить количество ТЛО класса «земля».

Было выполнено моделирование различных форм рельефа с разной плотностью точек лазерных отражений на 1 м2. Сравнение моделей с различной плотностью точек лазерных отражений на 1 м2 проводилось в программном продукте ГИС ArcGis [2]. Для этого создавалась регулярная сетка ячеек и в узлах сетки вычислялись высоты. Для оценки полученных моделей с разным количеством точек лазерных отражений, необходимых для отображения рельефа поверхности, от высот «плотной» ЦМР вычитались высоты «разреженных» ЦМР. Выполнялся статистический анализ полученных ошибок и средних квадратических погрешностей (СКП).

В качестве тестового участка был взят участок, с углом наклона до 40 , площадью 6124,17 м2. Участок расположен в лесной местности.

Общее количество точек лазерных отражений - 64250 точки, следовательно, 10.49 т/м2. Для данного участка было проведено моделирование рельефа и определено минимальное количество ТЛО на 1м2. 
Количество ТЛО на 1 м2 для различных ЦМР

Таблица 1

\begin{tabular}{|c|c|c|c|c|c|}
\hline \multicolumn{5}{|c|}{ Участок 2 } \\
\hline Площадь участка, м & \multicolumn{5}{c|}{6124,17} \\
\hline $\begin{array}{c}\text { Сравниваемые } \\
\text { поверхности }\end{array}$ & $\mathrm{Gr}$ _ & $\mathrm{Gr}_{-} 1$ & $\mathrm{Gr} 22$ & $\mathrm{Gr} 33$ & Gr_4 \\
\hline $\begin{array}{c}\text { Количество ТЛО } \\
\text { класса «Земля» }\end{array}$ & 12041 & 7224 & 6020 & 4013 & 3010 \\
\hline $\begin{array}{c}\text { Процент разрежения } \\
\text { ТЛО }\end{array}$ & $40 \%$ & $50 \%$ & $67 \%$ & $75 \%$ \\
\hline $\begin{array}{c}\text { Количество ТЛО на } \\
1 \text { м }^{2}, \mathrm{~T} / \mathrm{m}^{2}\end{array}$ & 1,97 & 1,18 & 0,66 & $\mathbf{0 , 4 9}$ & 0,39 \\
\hline
\end{tabular}

На рисунках 1 - 2 приведены примеры цифровых моделей рельефа с различной плотностью точек лазерных отражений.

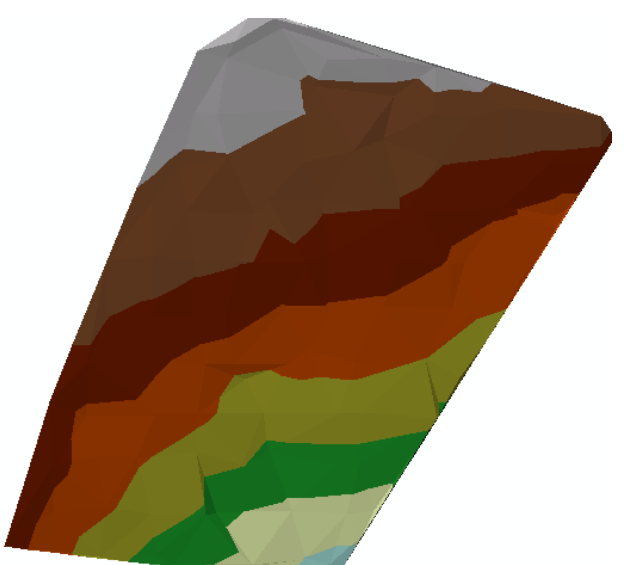

Рисунок 1 - ЦМР, созданная по всему классу «Земля». ТЛО $-1,97 \mathrm{~m} / \mathrm{s} 2$

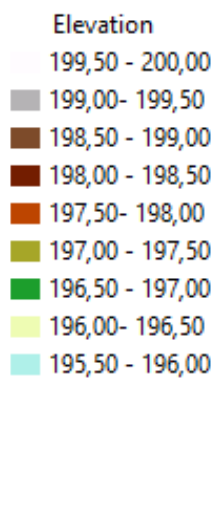

Elevation $199,50-200,00$

$199,00-199,50$

$198,50-199,00$

$198,00-198,50$

$197,50-198,00$

$197,00-197,50$

$196,50-197,00$

$196,00-196,50$

$195,50-196,00$

Сравниваемые GRID-поверхности с размером пикселя 1 м были созданы на основе узлов полигональных сеток с размером ячейки $-0,10 \times 0,10$ м.

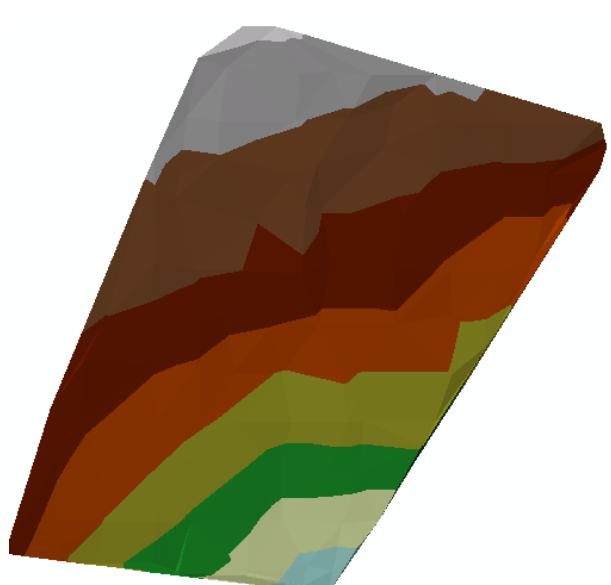

Рисунок 2 - ЦМР, состоящая из 0.49 $\mathrm{m} / \mathrm{M} 2$

Таблийа 2

Данные статистического анализа сравниваемых поверхностей для четвертого тестового (характерного) участка.

\begin{tabular}{|c|c|c|c|c|c|}
\hline \multicolumn{6}{|c|}{ Всхолмленный участок } \\
\hline Площадь участка, м2 & \multicolumn{5}{|c|}{6124,17} \\
\hline $\begin{array}{c}\text { Сравниваемые } \\
\text { поверхности }\end{array}$ & $\begin{array}{l}\mathrm{Gr}_{-} \mathrm{I} / \\
\mathrm{Gr}_{-1}\end{array}$ & $\begin{array}{l}\mathrm{Gr}_{-} \mathrm{I} / \\
\mathrm{Gr} 22\end{array}$ & $\begin{array}{l}\mathrm{Gr} \_\mathrm{I} / \\
\mathrm{Gr} 3\end{array}$ & $\begin{array}{l}\mathrm{Gr} \_\mathrm{I} / \\
\mathrm{Gr} 4\end{array}$ & $\begin{array}{l}\mathrm{Gr} \_\mathrm{I} / \\
\mathrm{Gr} 5\end{array}$ \\
\hline \multirow{2}{*}{$\begin{array}{c}\text { Количество ТЛО класса } \\
\text { «Земля» }\end{array}$} & 12041 & 12041 & 12041 & 12041 & 12041 \\
\hline & 7224 & 6020 & 4013 & 3010 & 2408 \\
\hline $\begin{array}{c}\text { Процент разрежения ТЛО, } \\
\%\end{array}$ & $40 \%$ & $50 \%$ & $67 \%$ & $75 \%$ & $80 \%$ \\
\hline Минимальная ошибка, м & $-0,12$ & $-0,14$ & $-0,17$ & $-0,25$ & $-0,25$ \\
\hline Максимальная ошибка, м & 0,14 & 0,16 & 0,16 & 0,19 & 0,20 \\
\hline СКП, $\mathrm{m}$ & 0,10 & 0,12 & 0,17 & 0,26 & 0,26 \\
\hline
\end{tabular}

В таблице 2 представлены данные статистического анализа сравниваемых цифровых моделей рельефа.

В итоге получилось, что для всхолмленного рельефа с углом наклона порядка 40 минимальное количество ТЛО на 1 м2 составляет 0,49 т/м2. 


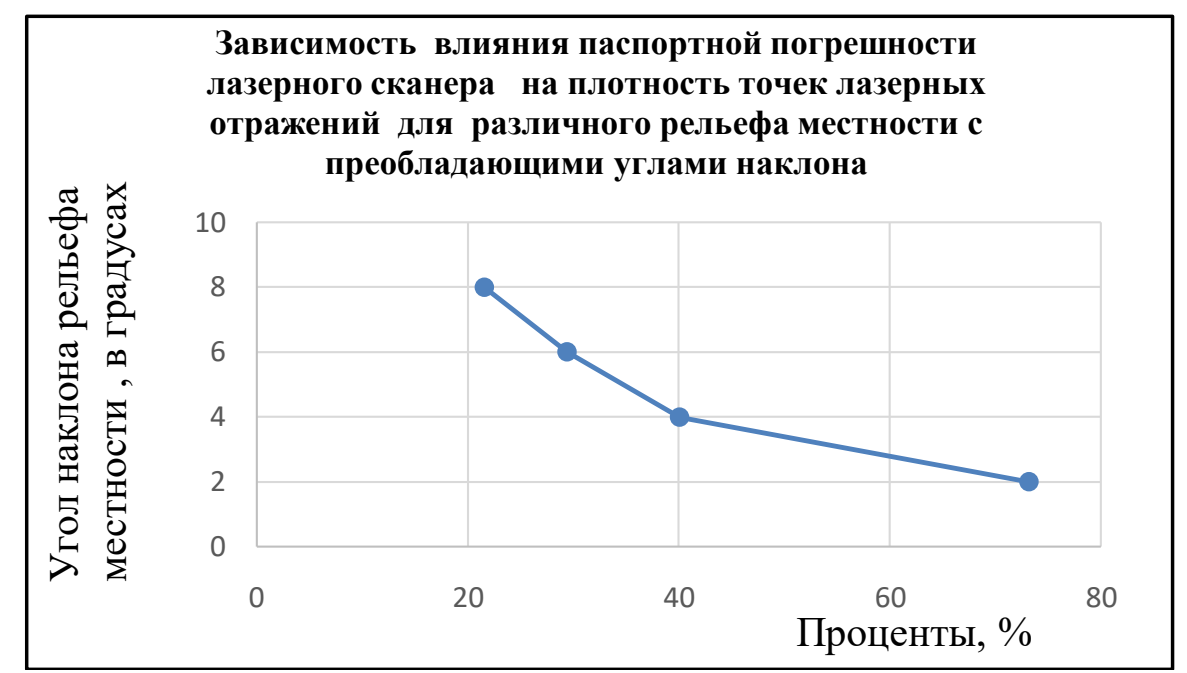

Рисунок 3 - График зависимости влияния паспортной погрешности лазерного сканера на плотность точек лазерных отражений для различного рельефа местности с преобладающими углами наклона

На рисунке 3 ось ординат представлена углами наклона рельефа местности, ось абсцисс - относительным отклонением между необходимой плотностью ТЛО с учетом влияния паспортной погрешности лазерного сканера и без учета этой погрешности. На графике наблюдается зависимость снижения прироста плотности точек лазерных отражений с увеличением преобладающих углов наклона рельефа местности. На основании этого можно сделать вывод, что для равнинной местности паспортная погрешность лазерного сканера имеет решающую роль для определения точек лазерных отражений на единицу площади. Однако при этом сохраняется рост плотности точек лазерных отражений с увеличением угла наклона рельефа местности (рисунок 4).

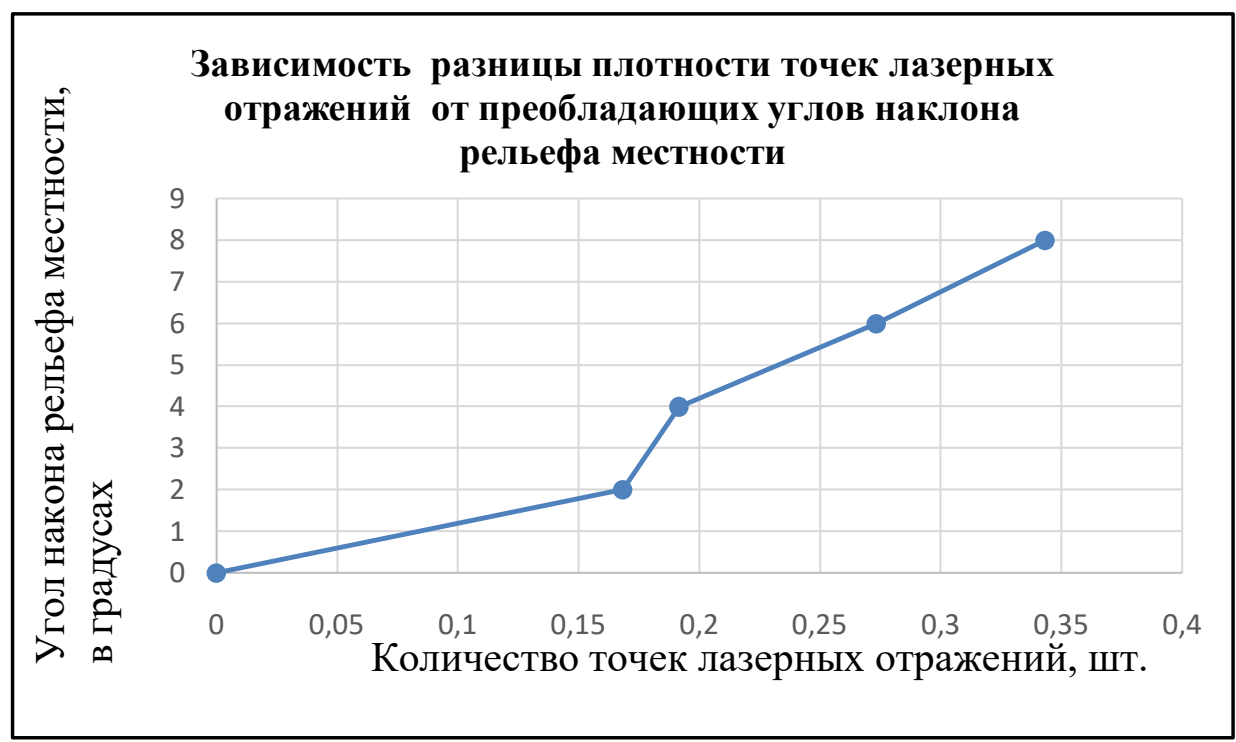

Рисунок 4 - График зависимости плотности точек лазерных отражений от преобладаюших углов наклона рельефа местности

Ниже представлены сводные таблицы результатов исследований на различные характеристики рельефа с преобладающими углами наклона [1] с учетом паспортной погрешности лазерного сканера $(\mathrm{m}=0.1 \mathrm{~m})$ и без учета этой погрешности. 
Таблиияа 2

Минимальное количество ТЛО на 1 м2 для всхолмленного рельефа местности

\begin{tabular}{|c|c|c|c|c|c|c|c|}
\hline $\begin{array}{c}\text { Характеристика } \\
\text { рельефа и } \\
\text { максимально } \\
\text { преобладающи } \\
\text { е углы наклона }\end{array}$ & $\begin{array}{c}\text { Характеристик } \\
\text { а } \\
\text { ЦМР }\end{array}$ & $\begin{array}{c}\text { Первый } \\
\text { тестовы } \\
\text { й } \\
\text { участок }\end{array}$ & $\begin{array}{c}\text { Второй } \\
\text { тестовы } \\
\text { й } \\
\text { участок }\end{array}$ & $\begin{array}{c}\text { Третий } \\
\text { тестовы } \\
\text { й } \\
\text { участок }\end{array}$ & $\begin{array}{c}\text { Четверты } \\
\text { й } \\
\text { тестовый } \\
\text { участок }\end{array}$ & $\begin{array}{c}\text { Пятый } \\
\text { тестовы } \\
\text { й } \\
\text { участок }\end{array}$ & $\begin{array}{c}\text { Шестой } \\
\text { тестовы } \\
\text { й } \\
\text { участок }\end{array}$ \\
\hline $\begin{array}{c}\text { Всхолмленны } \\
\text { й с углами } \\
\text { наклона до 40 }\end{array}$ & $\begin{array}{c}\text { без учета } \\
\text { паспортной } \\
\text { погрешности } \\
\text { лазерного } \\
\text { сканера }\end{array}$ & 0,49 & 0,48 & 0,47 & 0,46 & 0,48 & 0,49 \\
\hline $\begin{array}{c}\text { отражений на } 1 \\
\text { м }^{2}\end{array}$ & $\begin{array}{c}\text { с учетом } \\
\text { паспортной } \\
\text { погрешности } \\
\text { лазерного } \\
\text { сканера }\end{array}$ & 0,66 & 0,63 & 0,74 & 0,66 & 0,67 & 0,66 \\
\hline
\end{tabular}

В результате статистического анализа результатовмоделирования

Для всхолмленного рельефа с углами наклона до 40 без учета влияния паспортной погрешности лазерного сканера - минимальное количество точек лазерных отражений для создания цифровой модели рельефа составляет 0,48 т/м2. С учетом влияния паспортной погрешности лазерного сканера - 0,67 т/м2.

$$
* * *
$$

1. Инструкция по топографической съемке в масштабах 1:5000, 1:2000, 1:1000, 1:500: [ГКИНП-02-03382: введен 01.01.1983]. - М.: Недра, 1985. - 151 с.

2. Руководство пользователя ГИС ArcGIS.

\section{Қоңқыбаева А.Н. \\ Повышение перерабатывающей способности сортировочной горки с учетом элементов горочного цикла}

Карагандинский Государственный Технический Университет (Казахстан,Караганда)

doi:10.18411/spc-12-04-2018-24

idsp: 000001:spc-12-04-2018-24

Увеличение интенсивности движения поездов заставляет работать сортировочные станции в предельно допустимых нагрузках, что вызывает необходимость повышение перерабатывающей способности сортировочной горки и ее элементов с использованием современных технологий.

Сортировочная горка оборудована горочной автоматической централизацией (ГАЦ), устройствами автоматической локомотивной сигнализацией (АЛС), терминалами автоматической системы управления сортировочной станцией (АСУСС), радиотехническими устройствами типа ПБМ-56 и ДМ-88, устройствами пневмопочты, источниками энергоснабжения Ф1 и Ф2. Дежурный по сортировочной горке (ДСПГ) устанавливает очередность расформирования разборочных составов. При наличии в составах большого количества вагонов углового потока дежурный по горке, по согласованию со станционным диспетчером, планирует пропуск такого состава в другую сортировочную систему для расформирования. После обработке в парке приема прибывшего в расформирование поезда горочный локомотив заезжает в хвост состава, надвигает состав до горба горки и производит его роспуск. Таким образом, элементами горочного цикла при параллельном расположении парков приема и сортировочного являются: заезд, надвиг, роспуск и осаживание. 